\title{
Ultrasound as a first-line investigation to diagnose malrotation in children
}

\author{
Vineet Binu ${ }^{1}$ (D) Day Way Goh ${ }^{1} \cdot$ Ajay Taranath ${ }^{2} \cdot$ Lino Piotto $^{2} \cdot$ Roger Gent $^{2}$
}

Received: 6 June 2021 / Revised: 6 June 2021 / Accepted: 23 June 2021 / Published online: 10 August 2021

(C) Crown 2021

Dear Editors,

We commend the work done by the Texas Children's Hospital on the use of US in the diagnosis and management of intestinal malrotation [1,2]. A recent systematic review and meta-analysis further supports the use of US as the first line of investigation in the diagnosis of malrotation [3].

At our institution, we have been using US as the first line of imaging for malrotation since 2008 with the added modification of instilling normal saline via a nasogastric tube to delineate the entire course of the duodenum, and we first published the results in 2014 [4]. We have now published a further study with a much larger cohort of 539 patients with this technique and demonstrated a very high sensitivity and specificity and therefore a high degree of safety and efficacy in diagnosing malrotation in children [5]. We support the use of US in diagnosing malrotation but would strongly advocate the additional step of using saline to delineate the course of the duodenum, which is de facto a contrast study of the entire duodenal course to beyond the duodeno-jejunal flexure, but without exposure to ionizing radiation.

Strouse's [6] editorial posed the rhetorical question: Ultrasound for malrotation and volvulus - has the time come? Our response is: Yes it has; the time has come!

Vineet Binu

dr.vineet.binu9@gmail.com

1 Department of Paediatric Surgery, Women's and Children's Hospital, 72 William Road, North Adelaide, SA 5006, Australia

2 Department of Medical Imaging, Women's and Children's Hospital, North Adelaide, SA, Australia

\section{Declarations}

Conflicts of interest None

\section{References}

1. Nguyen HN, Navarro OM, Guillerman RP et al (2021) Untwisting the complexity of midgut malrotation and volvulus ultrasound. Pediatr Radiol 51:658-668

2. Nguyen HN, Sammer MBK, Ditzler MG et al (2021) Transition to ultrasound as the first-line imaging modality for midgut volvulus: keys to a successful roll-out. Pediatr Radiol 51:506-515

3. Nguyen HN, Kulkarni M, Jose J et al (2021) Ultrasound for the diagnosis of malrotation and volvulus in children and adolescents: a systematic review and meta-analysis. Arch Dis Child. https://doi. org/10.1136/archdischild-2020-321082

4. Hennessey I, John R, Gent R et al (2014) Utility of sonographic assessment of the position of the third part of the duodenum using water instillation in intestinal malrotation: a single-center retrospective audit. Pediatr Radiol 44:387-391

5. Binu V, Nicholson C, Cundy T et al (2021) Ultrasound imaging as the first line of investigation to diagnose intestinal malrotation in children: safety and efficacy. J Pediatr Surg. https://doi.org/10. 1016/j.jpedsurg.2021.04.009

6. Strouse PJ (2021) Ultrasound for malrotation and volvulus: has the time come? Pediatr Radiol 51:503-505

Publisher's note Springer Nature remains neutral with regard to jurisdictional claims in published maps and institutional affiliations. 